Research Article

\title{
Fracture Morphology Analysis of Frozen Red Sandstone under Impact
}

\author{
Yang Yang $\left(\mathbb{D},{ }^{1}\right.$ Niannian Zhang, ${ }^{2}$ and Jianguo Wang $\mathbb{D}^{3}$ \\ ${ }^{1}$ School of Civil and Resources Engineering, University of Science and Technology Beijing, Beijing 100083, China \\ ${ }^{2}$ Yunnan Superstar Certified Safety Engineer Office Co., Ltd., Kunming 650106, Yunnan, China \\ ${ }^{3}$ Faculty of Land Resources Engineering, Kunming University of Science and Technology, Kunming 650093, Yunnan, China
}

Correspondence should be addressed to Jianguo Wang; wangjg0831@163.com

Received 29 September 2021; Revised 13 November 2021; Accepted 3 December 2021; Published 23 December 2021

Academic Editor: Bangbiao Wu

Copyright (C) 2021 Yang Yang et al. This is an open access article distributed under the Creative Commons Attribution License, which permits unrestricted use, distribution, and reproduction in any medium, provided the original work is properly cited.

The deformation and failure characteristics of red sandstone under subzero temperature were studied by the split Hopkinson pressure bar (SHPB) dynamic impact test. The effects of different subzero temperatures on rock strength properties, fractal dimension, and dissipated energy were analyzed combined with microfracture morphology. The reasons for rock dynamic mechanical property deterioration under lower subzero temperatures were revealed. The research shows that low subzero temperature will cause "frostbite" of red sandstone. Under high strain rate loading, the rock will quickly lose its bearing capacity, and its dynamic mechanical strength will drop sharply. The dissipated energy $W_{\mathrm{L}}$ of the frozen rock specimen is positively correlated with the fractal dimension $D$ and closely related to the macroscopic failure characteristics. It could be concluded that greater dissipation energy leads to more serious damage of rock and accordingly results in a larger fractal dimension. Fracture morphology analysis shows that the lower subzero temperature generated remarkable cracks in the material interface of the red sandstone. The damage of the red sandstone could be explained by the fact that the crack tip had low plastic deformation ability under high strain rate loading and the composition of cement was vulnerable to the subzero temperature effect.

\section{Introduction}

As geotechnical engineering projects increase rapidly in the high-altitude area, it is of great interest to investigate the rock properties under subzero temperature. The rock will shrink and become dense when it encounters subzero temperature, which seems to increase in strength. However, the pore water of the rock will undergo water-ice phase transformation and result in swelling force. The huge swelling force will cause damage to the rock $[1,2]$. In addition, rock under subzero temperature is prone to brittle failure, which makes it difficult to predict the mechanical properties of rock under subzero temperature and high strain loading rate.

Currently, many researchers have conducted studies to describe the statics performance of rock under subzero temperature. For example, Aoki et al. [3] carried out a quasi-static uniaxial compression experiment and
Brazilian splitting experiment on a variety of rocks in the negative temperature region, and the results showed that the compressive tensile strength and elastic modulus of rocks increased significantly at $-160^{\circ} \mathrm{C}$. Also, Yamabe and Neaupane [4] tested the statics properties of sandstone at negative temperature through uniaxial and triaxial experiments and found that tensile and compressive strength of sandstone increased with the decrease of temperature, which was consistent with the law of previous experiments. However, the elastic modulus remained unchanged from $-10^{\circ} \mathrm{C}$ to $-20^{\circ} \mathrm{C}$ and was little affected by temperature. Again, Dwivedi et al. [5] tested the fracture toughness of eight kinds of rocks at low temperature by using the Brazilian disk experiment and found that the fracture toughness of rocks at negative temperature was significantly greater than that at normal temperature and indicated a linear growth relationship with the decrease of temperature. Tang et al. [6-10] studied the mechanical properties of a variety of rocks at 
negative temperatures $\left(-10^{\circ} \mathrm{C} \sim-50^{\circ} \mathrm{C}\right)$ through static and quasi-static mechanical experiments. The research results show that negative temperature has a great influence on the mechanical parameters of rocks, and the compressive strength, internal friction angle, cohesion, and elastic modulus of rocks increase with the decrease of temperature. However, the studies on dynamics of subzero temperature rocks are still scarce.

Fracture morphology studies the damage and failure characteristics of materials from a unique perspective of fracture [11-14], which is a very effective method for the analysis of microstructure, initiation and propagation of cracks, and irreversible deformation of materials. Accordingly, this paper carries out dynamic impact tests (SHPB) on red sandstone and obtains macroscopic failure characteristics and strength characteristics of red sandstone at subzero temperature under impact loading. After combining analysis with scanning electron microscopy (SEM), the effects of dynamic load, subzero temperature, and water-ice phase transformation on the strength and deformation properties of rock were studied by fractal dimension and fracture morphology.

\section{Failure Characteristics of Frozen Red Sandstone under Impact}

2.1. Experimental Scheme and Specimen Preparation. A $75 \mathrm{~mm}$ large-diameter SHPB experimental device (see Figure 1) was used to complete the dynamic impact tests of rock. The red sandstone from Inner Mongolia was adopted. Seven temperatures were selected in the tests, namely, $25^{\circ} \mathrm{C}$, $-5^{\circ} \mathrm{C},-10^{\circ} \mathrm{C},-15^{\circ} \mathrm{C},-20^{\circ} \mathrm{C},-30^{\circ} \mathrm{C}$, and $-40^{\circ} \mathrm{C}$. Driven by high-pressure gas of $0.72 \mathrm{MPa}$, rock failure occurred in the SHPB dynamic impact test, and the fractal characteristics and microscopic fracture morphology of red sandstone under high strain rate were studied. The experimental scheme is shown in Table 1.

$\mathrm{Li}$ and $\mathrm{Gu}$ [15] did a lot of experimental research on brittle materials like rocks. They found that when the length-diameter ratio of specimens is 0.5 , the inertia effect of brittle materials can be effectively reduced. The lengthdiameter ratio of cylindrical specimens in this test was determined to be 0.5 . On the contrary, the dispersion effect of stress wave propagation in bars and specimens requires the diameters of bars and specimens to be as small as possible. However, rock materials were characterized by heterogeneity and anisotropy, so the results of small-diameter specimens are not representative and cannot truly reflect the mechanical properties of rocks. According to the recommendation of international Society of Rock Mechanics (ISRM), the size of red sandstone specimen is designed as $\Phi 74 \times 37 \mathrm{~mm}$.

SHPB dynamic impact tests adopted a standard cylindrical specimen with a diameter of $74 \mathrm{~mm}$ and length of $37 \mathrm{~mm}$. In Figure 2, the voltage value of incident wave and reflected wave after superposition matches well with that of transmitted wave, which indicates that the rock specimens are in dynamic stress balance and the experimental results are reliable.

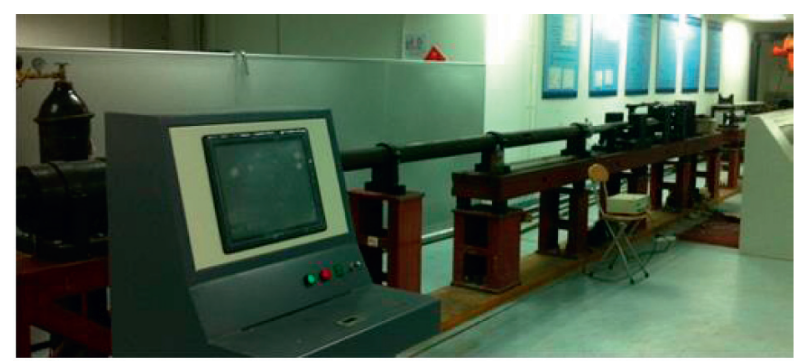

Figure 1: SHPB experimental system.

TABle 1: Experimental scheme.

\begin{tabular}{|c|c|c|c|c|}
\hline Rock type & Size $(\mathrm{mm})$ & $T\left({ }^{\circ} \mathrm{C}\right)$ & $P(\mathrm{MPa})$ & NT \\
\hline \multirow{7}{*}{ Red sandstone } & \multirow{7}{*}{$\Phi 74 \times 37$} & 25 & \multirow{7}{*}{0.72} & 4 \\
\hline & & -5 & & 4 \\
\hline & & -10 & & 4 \\
\hline & & -15 & & 4 \\
\hline & & -20 & & 4 \\
\hline & & -30 & & 4 \\
\hline & & -40 & & 4 \\
\hline
\end{tabular}

The preparation of low-temperature rock specimens is accomplished in the temperature-testing machine. After dropping to the specified temperature, the specimens need to be stabilized in the low-temperature chamber for at least $24 \mathrm{~h}$ to ensure the consistency of the temperature throughout the specimen. In order to keep the subzero temperature constant during the whole test, a temperature compensation device is added to the SHPB experimental system. The temperature compensation device is installed in the specimen loading area of the SHPB test system. After the specimen is installed in place, the container of the temperature compensation device is sealed. Under the action of the external refrigeration compressor, the specific negative temperature regulation is carried out on the sealed container. The specimen is kept in the container for a period of time until the internal and external temperatures are consistent, and then the impact test is carried out. The existence of the temperature compensation device can not only ensure the specimen to keep the temperature constant in the impact process but also effectively weaken the fluctuating influence of room temperature on the test.

2.2. Stress-Strain Curves of Red Sandstone at Different Temperatures. The stress-strain curves of saturated red sandstone at different temperatures were obtained by the SHPB impact test.

It can be seen from Figure 3 that, with the decrease of temperature in the range of $25^{\circ} \mathrm{C}-30^{\circ} \mathrm{C}$, the slope of the linear elastic section of the curve gradually increases, the elastic deformation section gradually increases, the crack growth section shortens, and the unloading section becomes steeper. On the contrary, the curve after $-30^{\circ} \mathrm{C}$ has a linear elastic segment with a lower slope, a shorter elastic deformation segment, a longer crack growth segment, and a slower unloading segment. This indicates that the physical state of red sandstone changes from the ductile-brittle state 


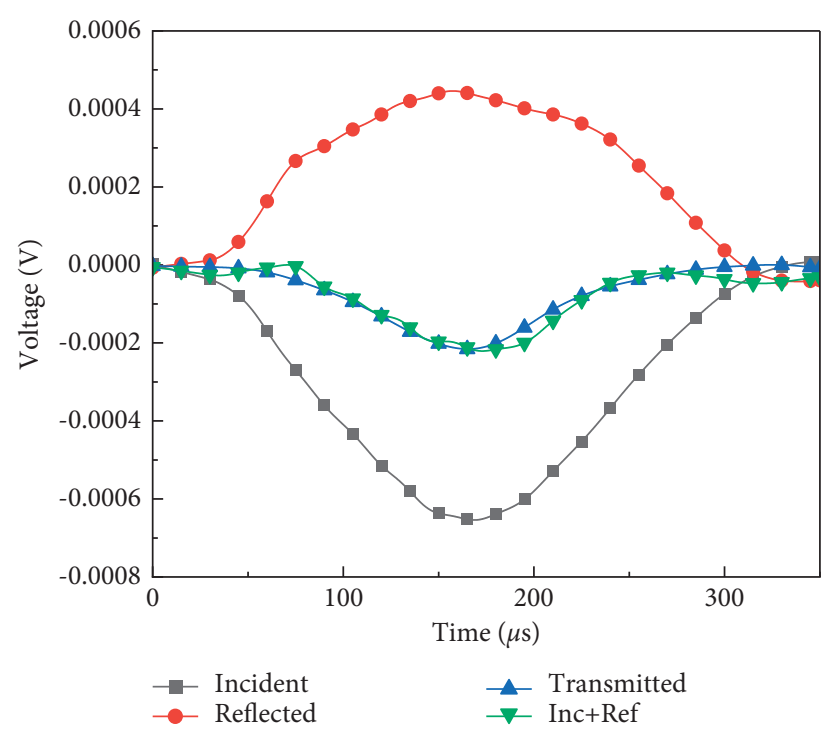

Figure 2: Dynamic stress balance curve.

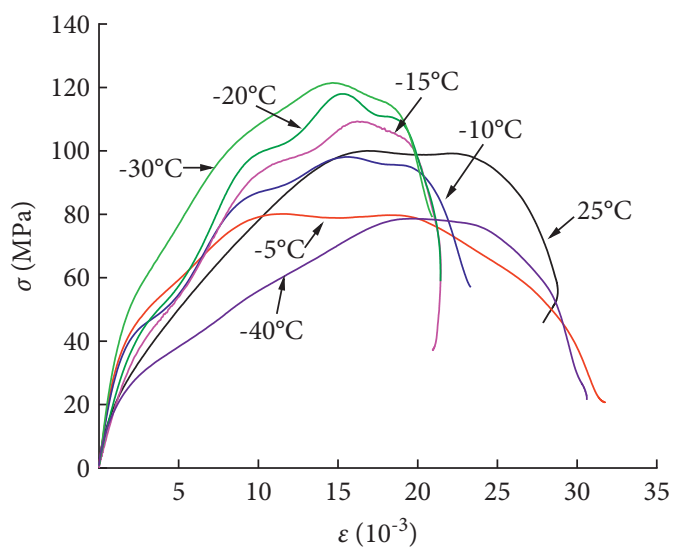

Figure 3: Stress-strain curves of red sandstone at different temperatures.

to brittleness in the transition stage from normal temperature to negative temperature $\left(25^{\circ} \mathrm{C}--30^{\circ} \mathrm{C}\right)$. However, at a lower temperature $\left(-40^{\circ} \mathrm{C}\right)$, the intensification of damage and the increase of microcracks in the rock lead to a great difference between the stress-strain curve and the transition stage.

An interesting phenomenon is also observed in Figure 3. In the previous static test of frozen red sandstone, the static strength of red sandstone gradually increases with the decrease of subzero temperature. However, in this test, the dynamic strength of red sandstone decreases sharply after $-30^{\circ} \mathrm{C}$, which is different from the static test results of frozen red sandstone.

2.3. Macroscopic Failure. The failure mode of the saturated red sandstone specimen at normal temperature is shown in Figure 4(a). By setting Figure 4(a) as baseline, the transformation of the red sandstone failure mode at different temperatures is explored.

At $25^{\circ} \mathrm{C}$, the specimen is subjected to strong axial compression under the action of compressive stress wave, and the outer rock expands radially, resulting in axial cracks. The rock specimen easily fractures and forms a large volume of tension splitting cylinder. After the stress wave passes through, part of the stored elastic deformation energy is released, and the rock particles produce reverse radial displacement, which easily generates circumferential fractures. A large number of small conical bodies are formed at the intersection of axial and circumferential fractures. Under the same impact pressure load, the failure modes of saturated red sandstone under different subzero temperatures are remarkably different. Firstly, at $-5^{\circ} \mathrm{C}$, the red sandstone fractures into several large pieces under the stress waves, and the failure surfaces are mostly inclined at $90^{\circ}$ angle with obvious tensile traces. From $-10^{\circ} \mathrm{C}$ to $-20^{\circ} \mathrm{C}$, the degree of rock fragmentation intensifies, and a large number of fragmentary fragments and a small number of conical structures appear in addition to the existence of tensile splitting bodies. From $-30^{\circ} \mathrm{C}$ to $-40^{\circ} \mathrm{C}$, the rock is further broken, and the broken body is mainly a small cone body with strong shear traces. In conclusion, the fracture degree of red sandstone at high strain rate is gradually intensified with the decrease of subzero temperature. The failure mode gradually changed from the tensile failure at the initial subzero temperature to the shear failure at lower subzero temperatures.

\section{Fractal Characteristics of Rock Fragmentation under Impact}

The standard screen (sieve diameter $0.075 \mathrm{~mm}$ to $53 \mathrm{~mm}$ ) was used to distinguish the broken blocks, and the mass of different grain groups (see Figure 5) after screening was counted. Based on the following equations, the fractal dimension was calculated through the accumulated screening mass and equivalent size [16-18]:

$$
\begin{aligned}
b & =\frac{\lg \left(M_{R} / M\right)}{\lg R}, \\
D & =3-b,
\end{aligned}
$$

where $b$ is the slope of the fitting function in the logarithmic coordinate system of $\lg R-\lg (\mathrm{MR} / \mathrm{M}) ; M_{R}$ is the cumulative screening mass of the broken body with particle size less than $R ; M$ is the mass of the specimen; and $D$ is the fractal dimension of fragmentation.

In order to obtain the data required for analysis, we need to make statistics on the screening quality of the red sandstone broken body under different particle sizes. The screen size is $0.075 \mathrm{~mm}, 0.15 \mathrm{~mm}, 0.3 \mathrm{~mm}, 0.6 \mathrm{~mm}, 1.18 \mathrm{~mm}$, $2.36 \mathrm{~mm}, 4.75 \mathrm{~mm}, 9.5 \mathrm{~mm}, 13.2 \mathrm{~mm}, 16 \mathrm{~mm}, 19 \mathrm{~mm}$, $26.5 \mathrm{~mm}, 31.5 \mathrm{~mm}, 37.5 \mathrm{~mm}$, and $53 \mathrm{~mm}$. There are a total of 15 grades of sieve holes, and the mass weighing of each grade of rock broken body after screening is recorded. Table 2 shows the lumpiness screening results and fractal dimensions of the SHPB dynamic impact test of red sandstone at different temperatures.

On the basis of dynamic impact tests, the incident energy $W_{I}$, reflected energy $W_{R}$, and transmitted energy $W_{T}$ of each 


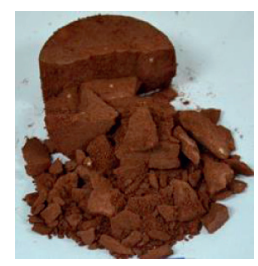

(a)

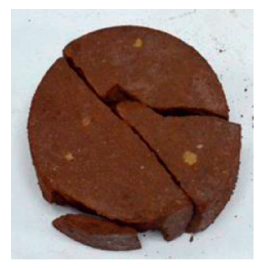

(b)

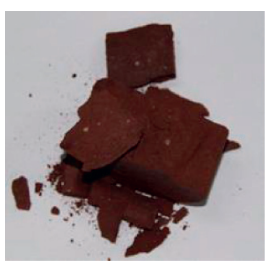

(c)

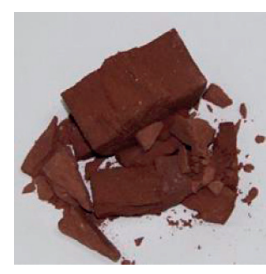

(d)

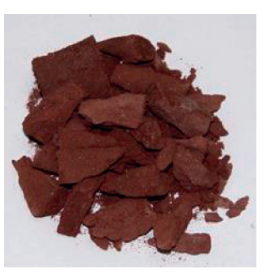

(e)

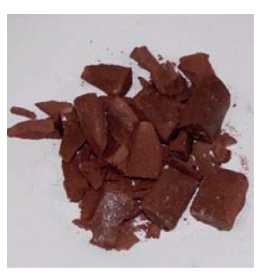

(f)

Figure 4: Failure modes of saturated red sandstone at different temperatures: (a) $25^{\circ} \mathrm{C}$, (b) $-5^{\circ} \mathrm{C}$, (c) $-10^{\circ} \mathrm{C},(\mathrm{d})-20^{\circ} \mathrm{C}$, (e) $-30^{\circ} \mathrm{C}$, and (f) $-40^{\circ} \mathrm{C}$.

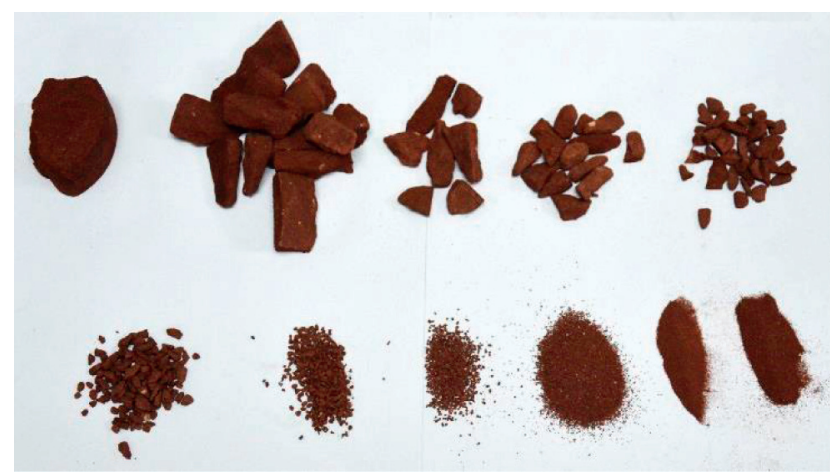

Figure 5: Specimen screening sample.

specimen in the SHPB system were obtained based on system energy analysis [19], and the corresponding dissipated energy $W_{\mathrm{L}}$ was obtained through

$$
W_{L}=W_{I}\left(W_{R}+W_{T}\right)
$$

Table 3 summarizes the data obtained from SHPB dynamic impact tests and equation (3).

Fractal dimension can be used to establish the relationship between dissipated energy and degree of fragmentation, so it is expected to use fractal dimension as a bridge to study the dissipated energy of material at higher strain rates through degree of fragmentation, especially for those that cannot be directly measured, such as the dissipated energy of rock under explosion load. Therefore, fractal dimension and dissipated energy are fitted, as shown in Figure 6.

It can be seen from the curve in Figure 6 that the fractal dimension is closely related to the dissipated energy, which shows a weak power function increasing relationship. This relationship is established based on damage and fracture and irrelevant to temperature or other external conditions. The curve of dissipated energy-fractal dimension is generally convex, and the growth ratio represented by the slope of the curve tends to gradually slow down. Moreover, the emergence and size of the threshold are related to the sieve aperture and mineral particle size. Combined with the aforementioned macroscopic fracture characteristics, the value of dissipated energy depends on the degree of rock breakage. The larger the dissipated energy is, the more serious the rock breakage is, and the larger the corresponding fractal dimension is. The relation between the dissipated energy and the fractal dimension satisfies the following weak power function:

$$
\begin{aligned}
D_{\text {ave }} & =-5.18123 \times 10^{-5} W_{L}^{2}+0.01972 W_{L}+0.58682, \\
R^{2} & =0.99788 .
\end{aligned}
$$

\section{Mesoscopic Fracture Characteristics}

Rock is a brittle material in a macroscopic perspective, and its fractures have significant brittle failure characteristics [20-22]. However, in a broad view, uniform plastic deformation can hardly be observed before fracture even if in the brittle material, and local plastic deformation may still occur in the fracture process. Therefore, this section divides rock fracture into brittle fracture, quasi-cleavage fracture, and ductile fracture according to the microscopic fracture morphology.

4.1. Brittle Fracture. Brittle fracture reflects the brittle failure characteristics of rock. The microscopic fracture of rock under impact load is mainly transgranular fracture and intergranular fracture, which can be classified into cleavage fracture and intergranular fracture according to the microscopic fracture morphology.

4.1.1. Cleavage Fracture. Cleavage fracture is a process of rock separation along some specific cleavage planes under impact load. It is a transgranular low-energy fracture phenomenon caused by the destruction of interatomic bond. In the SEM images of low magnification, the cleavage fracture surface is smooth, but due to the lattice defects of the rock crystal itself and the microscopic morphology changes in the failure process, the cleavage fracture at high magnification will have a variety of characteristic microscopic morphology, such as river pattern and step pattern.

(1) River Pattern. This is the most representative fracture feature of brittle materials such as rock. Its formation could be explained by the fact that when there are defects in the crystal of the material, the material is separated along a series of crystal planes at different heights instead of a certain plane, so that a series of steps arise on the surface of the fracture. Due to the nearly same force, all steps have the same style. In the process of crystal separation and crack growth, a series of steps with close spacing will merge layer by layer, forming the river pattern as shown in Figure 7. 
TABLE 2: Grade of screening and fractal dimension for red sandstone under dynamic impact.

\begin{tabular}{|c|c|c|c|c|c|c|c|c|c|c|c|c|c|c|c|c|}
\hline \multirow{2}{*}{ Number } & \multicolumn{16}{|c|}{$d(\mathrm{~mm})$} \\
\hline & 0.075 & 0.15 & 0.3 & 0.6 & 1.18 & 2.36 & 4.75 & 9.5 & 13.2 & 16 & 19 & 26.5 & 31.5 & 37.5 & 53 & $D$ \\
\hline SRUC-25-1 & 4.7 & 8.6 & 10.6 & 6 & 12.1 & 33.5 & 61.3 & 66.4 & 4 & 32.7 & 73 & 0 & 74.5 & 4.7 & 8.6 & 2.32947 \\
\hline SRUC-25-2 & 5.8 & 13.3 & 17.7 & 7.3 & 13.1 & 28.3 & 53.7 & 47.5 & 22.4 & 19.4 & 36.4 & 31.9 & 32.9 & 57.7 & 0 & 2.42209 \\
\hline SRUC-25-3 & 2.1 & 7.9 & 25.1 & 8 & 14.2 & 29 & 53.8 & 48.2 & 45.4 & 0 & 71.7 & 0 & 33.3 & 58.3 & 2.1 & 2.36009 \\
\hline SRUC-5-1 & 0.3 & 0.4 & 0.4 & 0.3 & 0.3 & 1.2 & 0 & 1.9 & 1.9 & 4.5 & 32.4 & 0 & 0 & 0 & 345 & 2.15302 \\
\hline SRUC-5-2 & 0.5 & 0.7 & 0.6 & 0.3 & 0.8 & 1.8 & 2.3 & 8.1 & 5.2 & 15.5 & 34.2 & 0 & 0 & 58.6 & 265.5 & 2.12067 \\
\hline SRUC-5-3 & 0.7 & 0.6 & 0.7 & 0.5 & 1.1 & 2.8 & 6.3 & 6.2 & 5.1 & 7.5 & 54.3 & 0 & 58 & 250.5 & 0 & 2.08667 \\
\hline SRUC-10-1 & 2.6 & 2.5 & 3 & 1.4 & 3.2 & 10.6 & 22 & 16.3 & 26.7 & 21.4 & 120.6 & 56.4 & 0 & 104.7 & 0 & 2.22649 \\
\hline SRUC-10-2 & 4.6 & 6.6 & 10.3 & 6.3 & 10.7 & 18.6 & 38.5 & 20.5 & 41.4 & 22.6 & 147 & 16.3 & 0 & 0 & 0 & 2.34452 \\
\hline SRUC-10-3 & 2.1 & 7.9 & 25.1 & 8 & 14.2 & 29 & 53.8 & 48.2 & 45.4 & 0 & 71.7 & 0 & 33.3 & 58.3 & 0 & 2.29959 \\
\hline SRUC-20-1 & 7.4 & 2.2 & 2.5 & 1.4 & 3.5 & 8.9 & 19.8 & 18.6 & 23.1 & 36.9 & 66.8 & 34 & 52.5 & 107.8 & 0 & 2.37579 \\
\hline SRUC-20-2 & 3.7 & 3.7 & 3.1 & 1.6 & 3.7 & 9.2 & 19.4 & 23.7 & 11.2 & 64.2 & 132.1 & 32.7 & 0 & 80.7 & 0 & 2.27609 \\
\hline SRUC-20-3 & 3.9 & 3.8 & 4.1 & 2.1 & 5.1 & 13.9 & 29.6 & 35 & 16.4 & 64.7 & 149.2 & 18.1 & 41.5 & 0 & 0 & 2.39839 \\
\hline SRUC-30-1 & 2.5 & 4.3 & 3.5 & 1.2 & 2.2 & 5.6 & 13.4 & 5.7 & 22.5 & 37.3 & 83.2 & 0 & 30.9 & 168.7 & 0 & 2.35326 \\
\hline SRUC-30-2 & 0.5 & 0.7 & 0.6 & 0.3 & 0.8 & 10.8 & 12.3 & 18.1 & 15.2 & 25.5 & 34.2 & 52.3 & 60.8 & 78.6 & 92.4 & 2.43067 \\
\hline SRUC-30-3 & 0.6 & 0.7 & 0.7 & 4 & 10 & 26 & 14.6 & 25 & 62 & 33 & 55.4 & 60 & 50.7 & 48 & 79.1 & 2.44847 \\
\hline SRUC-40-1 & 15.8 & 13.3 & 17.7 & 17.3 & 23.1 & 28.3 & 43.7 & 47.5 & 32.4 & 19.4 & 36.4 & 31.9 & 27.7 & 32.9 & 0 & 2.45002 \\
\hline SRUC- $40-2$ & 13.3 & 14.6 & 16.2 & 14.1 & 10.5 & 23 & 24.6 & 25 & 32 & 41 & 45.4 & 50 & 45.7 & 45 & 0 & 2.43218 \\
\hline
\end{tabular}

TABLE 3: Energy distribution and fractal dimension.

\begin{tabular}{lccccr}
\hline$T\left({ }^{\circ} \mathrm{C}\right)$ & $\sigma(\mathrm{MPa})$ & $W_{I}(\mathrm{~J})$ & $W_{R}(\mathrm{~J})$ & $W_{T}(\mathrm{~J})$ & $W_{L}(\mathrm{~J})$ \\
\hline 25 & 98.51 & 530.11 & 219.01 & 163.47 & 147.63 \\
-5 & 102.47 & 524.89 & 162.28 & 253.51 & 109.10 \\
-10 & 113.16 & 531.57 & 160.52 & 239.42 & 131.63 \\
-20 & 121.01 & 529.26 & 184.24 & 199.71 & 145.05 \\
-30 & 122.12 & 531.61 & 207.04 & 165.79 & 1201 \\
-40 & 56.23 & 527.96 & 239.81 & 119.02 & 2.2902 \\
\hline
\end{tabular}

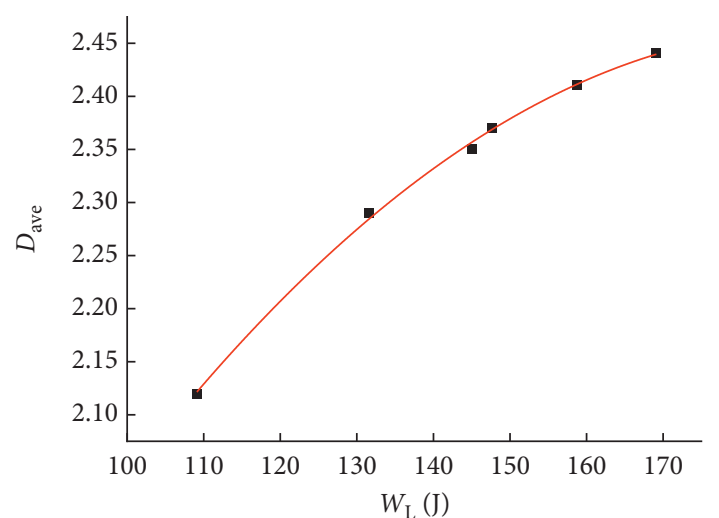

Figure 6: Fracture energy vs. fractal dimension for red sandstone.

(2) Step Pattern. Figure 8 shows the step pattern on the fracture surface of red sandstone. The mechanism of step pattern is the same as that of river pattern, but the cleavage plane of step pattern does not converge. Under impact load, the cleavage steps are arranged along the direction of crack propagation and perpendicular to the crack surface, which requires less free surface energy.

(3) Fan-Shaped Pattern. This is also called the feather pattern. As shown in Figure 9, the cleavage cracks originate from inside the crystal and spread outward in a fan-shaped way. The river pattern and the step pattern can be regarded as the fan bones supporting the fan surface.

(4) Wallner Line. This is a microscopic morphology formed by the interaction between the front end of crack propagation and the spherical shock wave centered on the defect. It reflects that the material is destroyed in the elastic deformation stage, no plastic deformation occurs in the whole process, and the separation mode is irrelevant to the crystal structure. When the brittle rock is at a lower temperature, the fracture morphology of Wallner line also appears. Figure 10 shows the fracture morphology of Wallner line of red sandstone.

(5) Secondary Crack. The secondary crack on the cleavage plane of rock is perpendicular to the direction of main crack propagation. Figure 11 shows the secondary crack on the cleavage plane of red sandstone under impact load.

(6) Lamellar Tearing Fracture. Figure 12 shows the lamellar tearing fracture on the surface of the broken red sandstone. Lamellar tearing fracture is a typical transgranular fracture morphology of rock materials under impact load. Sedimentary rocks are rich in layered structures after experiencing complex geological tectonic movements. Under low temperature and impact load, the original cracks in rocks can rapidly expand among the layered structures. However, due to the anisotropy of rock material, brittleness under subzero temperature, influence of soft interlayer structure, 


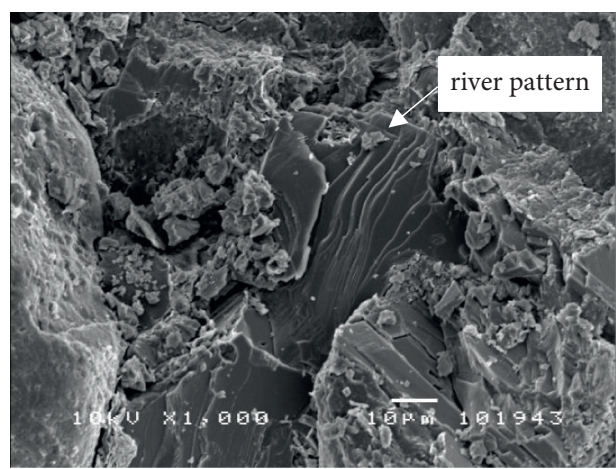

(a)

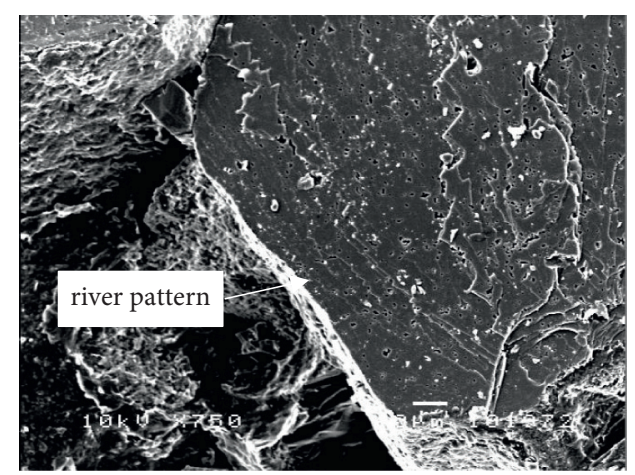

(b)

Figure 7: River pattern: (a) $-40^{\circ} \mathrm{C}$, red sandstone, $\times 1000$; (b) $25^{\circ} \mathrm{C}$, red sandstone, $\times 750$.

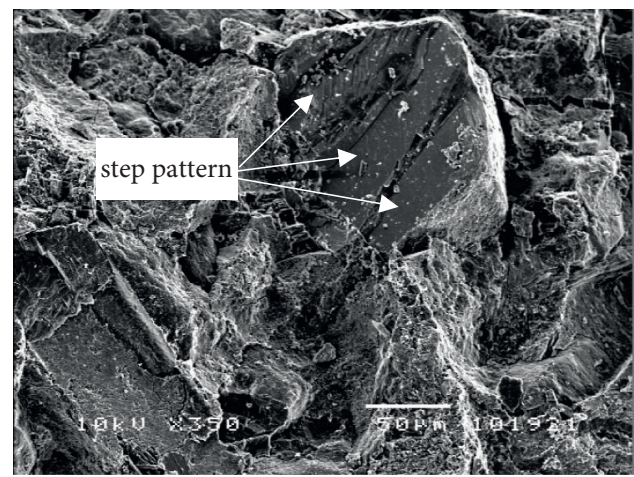

(a)

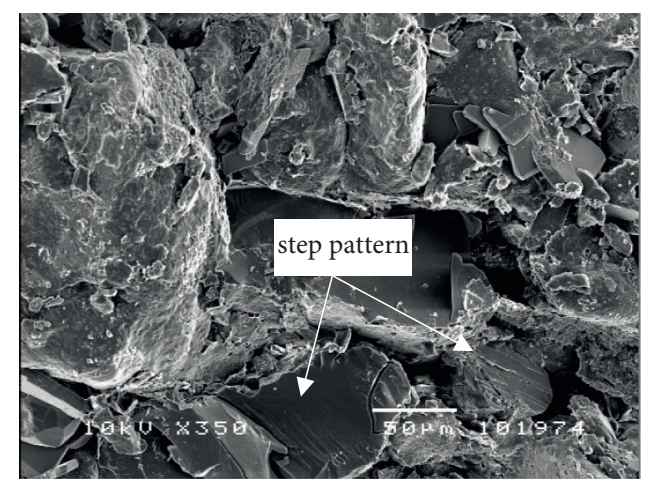

(b)

Figure 8: Step pattern: (a) $-20^{\circ} \mathrm{C}$, red sandstone, $\times 350$; (b) $-5^{\circ} \mathrm{C}$, red sandstone, $\times 350$.

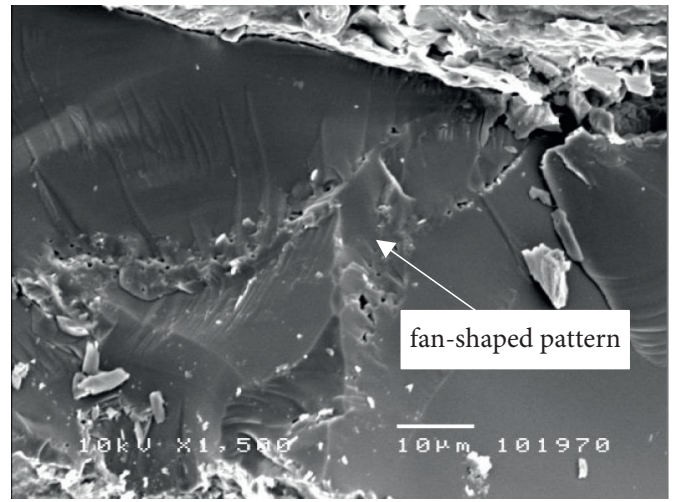

Figure 9: Fan-shaped pattern.

internal impurities, and second phase material, the secondary cracks easily occur in the process of crack propagation, which makes the fracture of rock appear rough at the stratified structural plane. According to the SEM scanning, it is found that the microfracture looks like a lamellar tear, so it is called the lamellar tear fracture.

Lamellar tearing fracture is a unique brittle transgranular fracture of rock, which rarely occurs in metal materials. Its formation mechanism is similar to the step pattern.

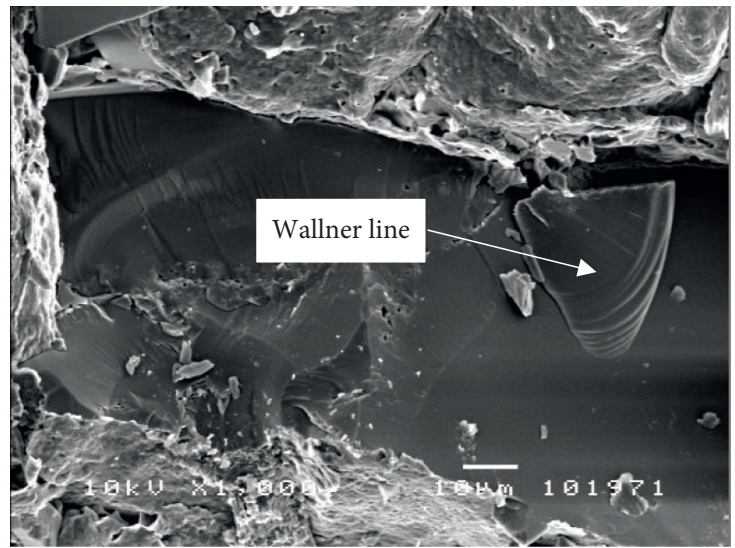

FIGURE 10: Wallner line.

However, due to the influence of lamellar and internal impurities, soft structure, and defects, the surface of fracture appears rough, and some rocks have prominent grain, thus forming a rough fracture similar to the step pattern.

4.1.2. Intergranular Fracture. Different from crystal cleavage fracture, intergranular fracture is another kind of microscopic morphology of brittle fracture, and its formation 


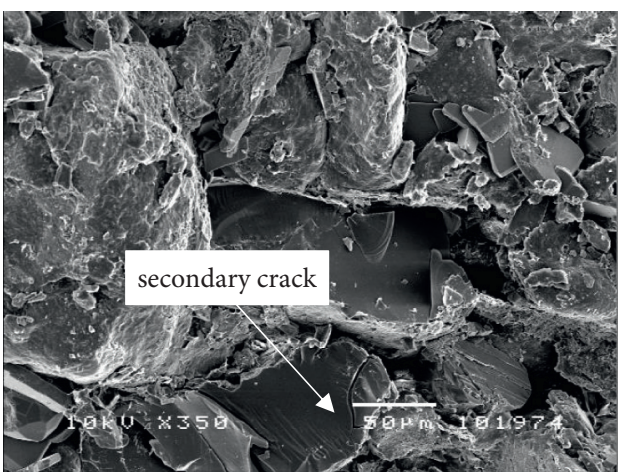

(a)

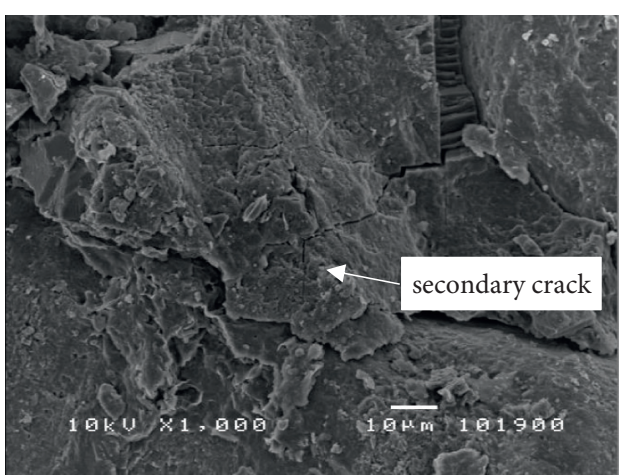

(b)

Figure 11: Secondary crack: (a) $25^{\circ} \mathrm{C}$, red sandstone, $\times 150$; (b) $-40^{\circ} \mathrm{C}$, red sandstone, $\times 1000$.

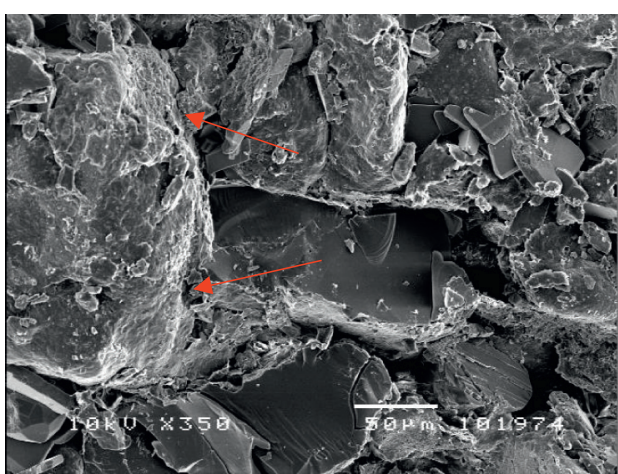

(a)

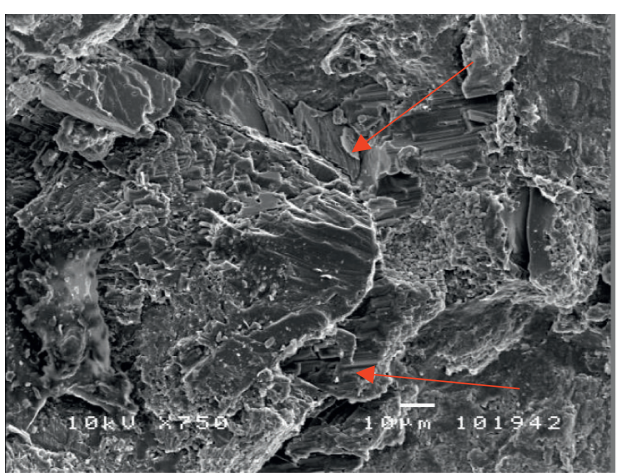

(b)

FIgURE 12: Lamellar tearing fracture: (a) $-40^{\circ} \mathrm{C}$, red sandstone, $\times 350$; (b) $25^{\circ} \mathrm{C}$, red sandstone, $\times 750$.

has a strong relationship with the stress state of the material. As can be seen from Figure 13, intergranular fracture crystals or particles generally remain intact and have a strong threedimensional sense. Their shapes are polyhedral or rock sugar patterns, and the grain boundary planes between adjacent particles are smooth without obvious characteristic morphology.

4.2. Ductile Fracture. Ductile fracture refers to the process accompanied by local deformation during crack propagation. A material with no dislocation at the tip as the crack propagates within the material can be defined as brittle in nature, but a material is ductile in nature if the crack propagates with dislocation nucleation at the tip or with activation of a dislocation source near the tip. When the material fracture is relatively smooth, it cannot be considered a brittle fracture. Many fracture examples show that flat fracture at low observation times unexpectedly exhibits ductility after magnifying observation times. Therefore, the difference between ductile fracture and brittle fracture is not obvious. In many cases, the type of fracture needs to be determined by the observation scale of the fracture surface. Figures 14-16 show the ductile fracture morphology of rock under impact load.
4.2.1. Parallel Slip Line Pattern. Slip separation is a common fracture morphology in ductile fracture. Under impact load, rock grains slip along the separation surface, resulting in many linear traces on the fracture surface. Such significant slip separation texture can be observed locally by SEM.

4.2.2. Stripe Pattern. A series of linear parallel fringes can be found in some rock fractures under low-magnification observation, which are called the stripe pattern.

4.2.3. Shear Band Pattern. The deformation of some rocks depends on the formation of a highly localized dense shear stress zone in the material, and the rock will fracture and separate in the direction parallel to the shear stress zone, thus forming shear band patterns on the separation interface.

4.3. Quasi-Cleavage Fracture. Quasi-cleavage is used to describe brittle cleavage fracture of polyphase materials with fine-scale polymerization; currently, it is applied to fracture involving both crystal cleavage and ductile cleavage. It is also called a transition fracture between cleavage and ductile fracture. The quasi-cleavage fracture is relatively smooth in macro, but it has both the meso-morphology of cleavage fracture and the characteristic texture of ductile fracture. 


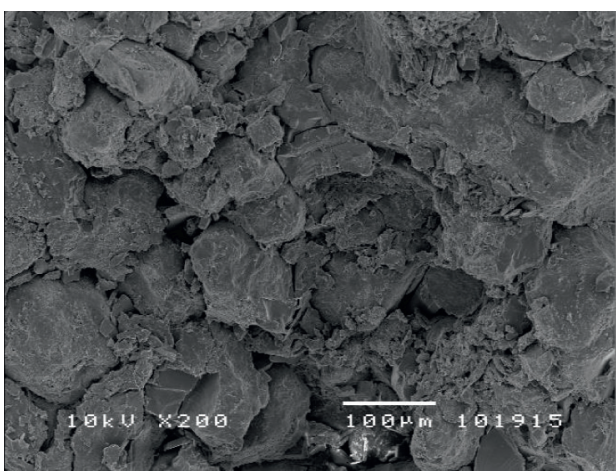

(a)

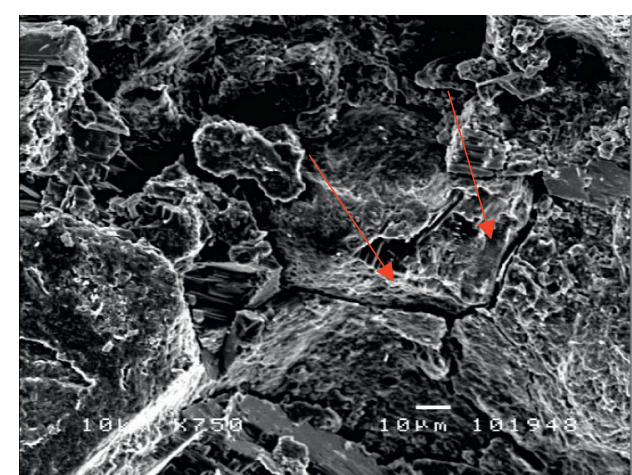

(b)

Figure 13: Intergranular fracture: $(\mathrm{a})-30^{\circ} \mathrm{C}$, red sandstone, $\times 200$; (b) $-20^{\circ} \mathrm{C}$, red sandstone, $\times 750$.
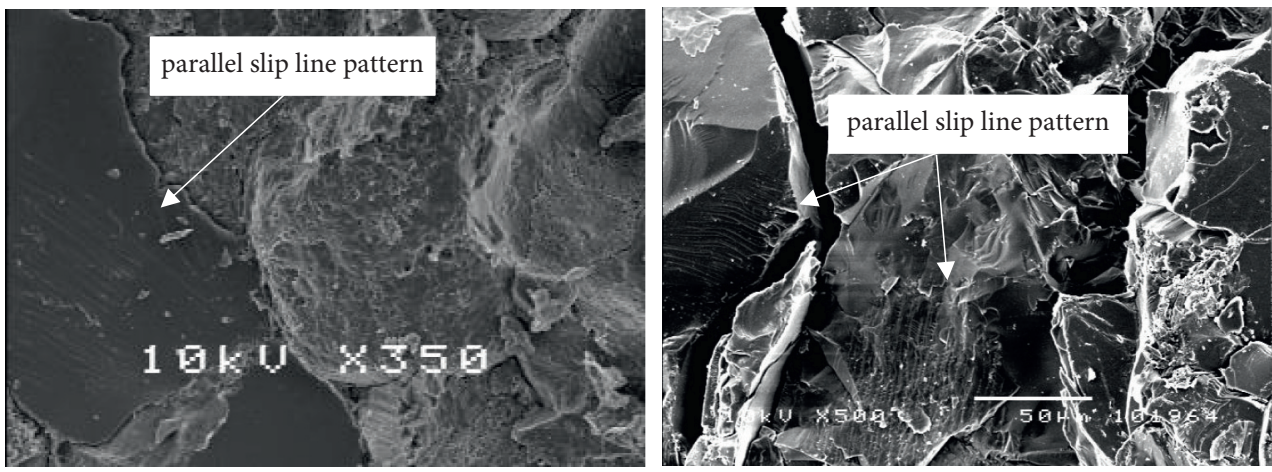

Figure 14: Parallel slip line pattern.

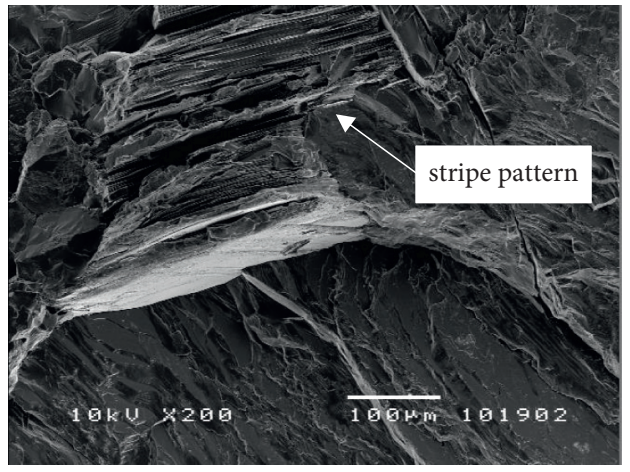

Figure 15: Stripe pattern.

Therefore, the quasi-cleavage fracture may present a variety of meso-morphology such as step, river, tear ridge, and strip patterns, slip line, and secondary crack. Figure 17 shows the mesoscopic morphology of quasi-cleavage fracture of the red sandstone under impact load.

4.4. Fracture Morphology Analysis of Red Sandstone Frozen at Subzero Temperature. The fracture morphology of saturated red sandstone at different temperatures is observed in order to explore the deterioration mechanism of dynamic mechanical properties of rock.
Red sandstone is a multiphase material composed of mineral particles, cementation, and remarkable voids. Under subzero temperature, the rock will shrink, some voids will close, and the connection between the components will become closer $[23,24]$. Compared with that of the normal temperature fracture, the roughness of the microscopic fracture is lower, the mineral particles can be seen but the three-dimensional sense is lower, and the integration with the surrounding cement and other matrix components is significant (see Figures 18(a)-18(c), $\times 150$ represents a magnification of 150 times). The rock is more compact and has higher strength as a whole. However, at lower subzero temperatures, due to the great difference in shrinkage rate and amplitude among mineral particles, ice media, cementation components, and other media, the separation phenomenon between components becomes apparent, and the three-dimensional sense of fracture morphology is enhanced. The mineral particles are prominent, and the cementation and matrix components are broken in disorder (see Figures 18(d) and 18(e)). Meanwhile, a large number of pores and microcracks will be generated at the interfaces of the media (see Figure 19). Under dynamic load, these defective structures and microcracks develop rapidly and even expand unstably, resulting in component separation, particle stripping, and other fracture phenomena under shear.

According to the observation of fracture morphology in Figure 19 ( $\times 350$ represents a magnification of 350 times $)$, it 

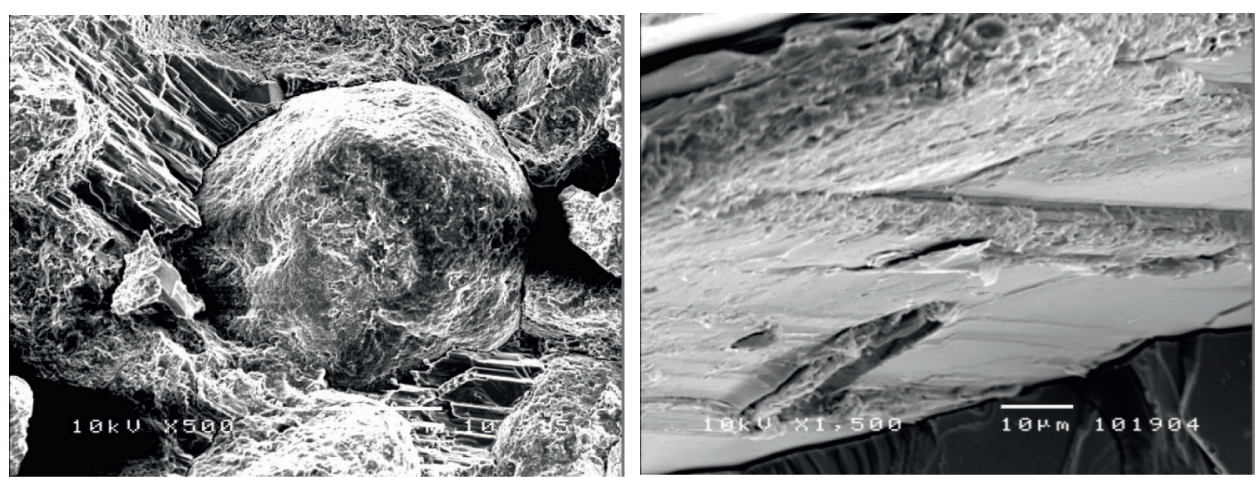

FIGURE 16: Shear band pattern.

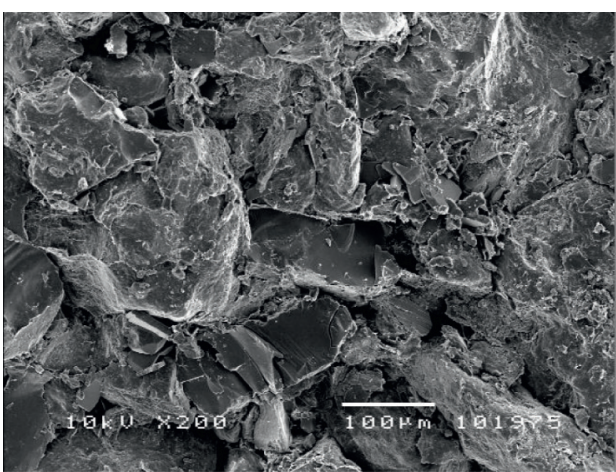

(a)

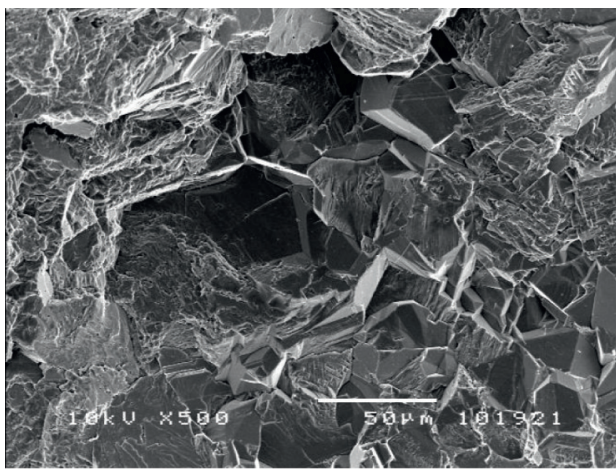

(b)

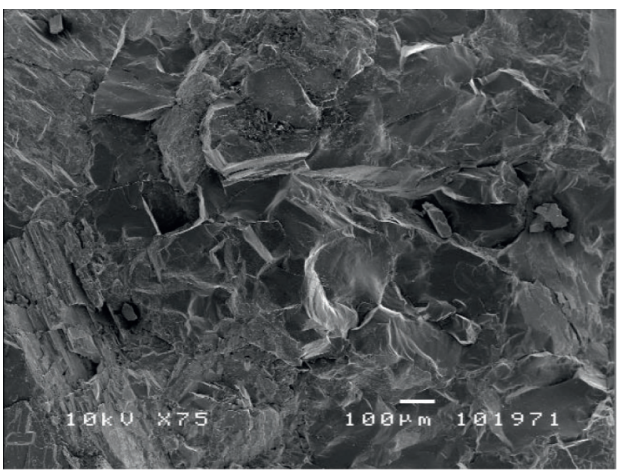

(c)

Figure 17: Quasi-cleavage fracture: (a) $-40^{\circ} \mathrm{C}$, red sandstone, $\times 200$; (b) $25^{\circ} \mathrm{C}$, red sandstone, $\times 500$; (c) $-40^{\circ} \mathrm{C}$, red sandstone, $\times 75$.

can be found that the fracture modes of saturated frozen red sandstone are mainly cement fracture and brittle fracture. Due to the complex mineral composition of the cementitious materials, they were more susceptible to cold temperature. Therefore, under the multiple influential factors of dynamic load and cold temperatures, it was found that the damage occurred at the cementitious materials first, which then caused the fracture of the red sandstone as a whole.

4.5. Analysis of Crack Nucleation under Subzero Temperature. The fracture morphology shows that the crack nucleation of frozen red sandstone under impact is mainly caused by the following two reasons.
4.5.1. Crack Nucleation Caused by Elastic Incompatibility between Grains. Red sandstone is composed of mineral grains and cement grains. Due to the difference in the crystal orientation, physical structure, and chemical composition of different kinds of grains, there must be a significant difference in their elastic modulus $[25,26]$. This means that different elastic strains will be generated between two adjacent grains under external impact loads, which may lead to local high stress and be released by forming cracks (see Figure 20).

4.5.2. Crack Nucleation Caused by Shear Deformation inside Grains. The fracture morphology shows that red sandstone is prone to shear deformation at low temperature, especially 


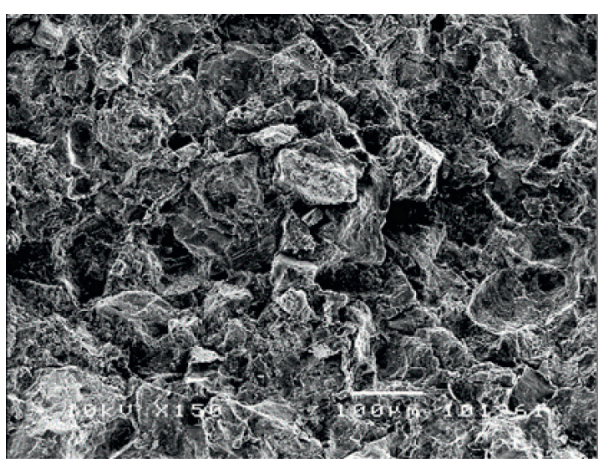

(a)

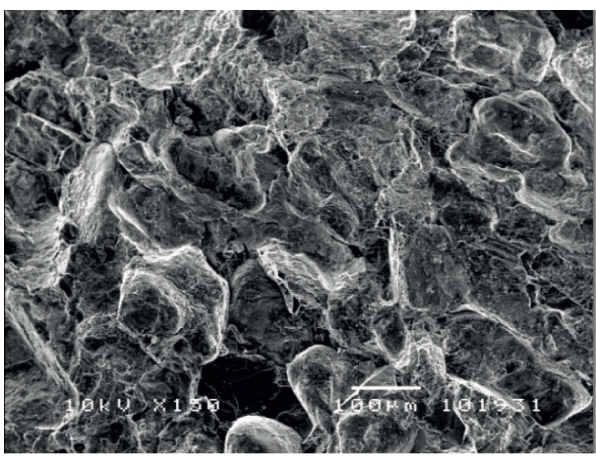

(c)

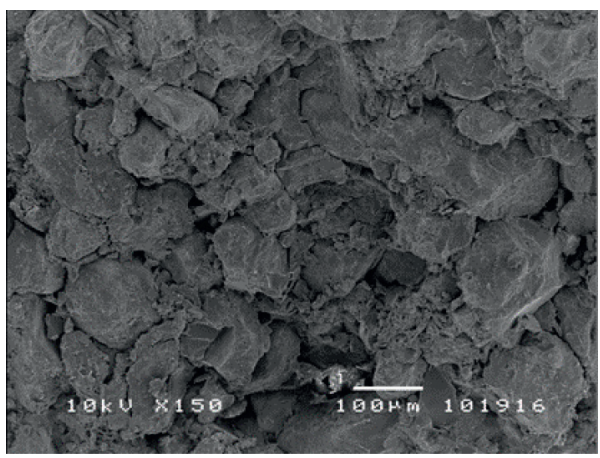

(e)

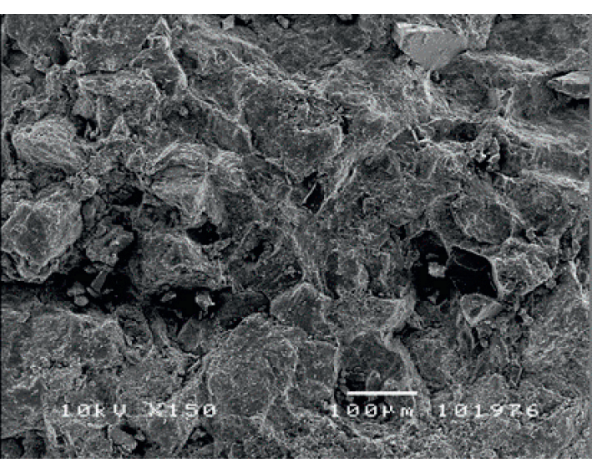

(b)

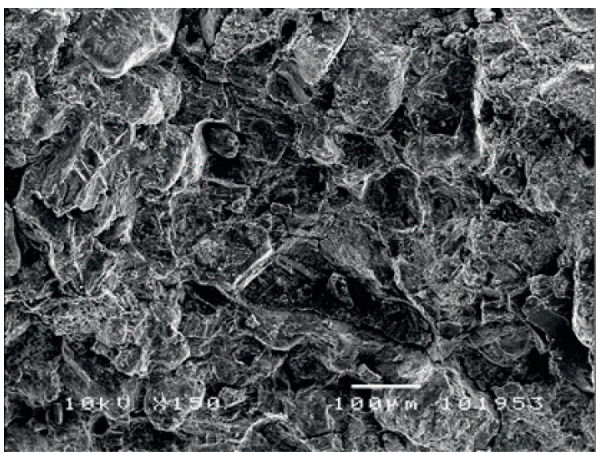

(d)

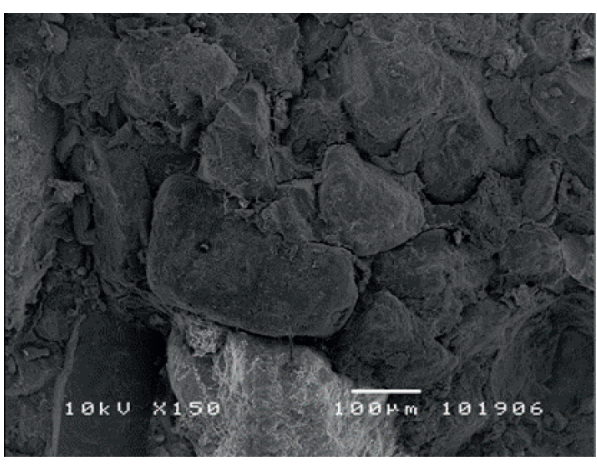

(f)

Figure 18: Fracture morphology of red sandstone at different temperatures: (a) $25^{\circ} \mathrm{C}$, red sandstone, $\times 150$; (b) $5^{\circ} \mathrm{C}$, red sandstone, $\times 150$; (c) $-10^{\circ} \mathrm{C}$, red sandstone, $\times 150$; (d) $-20^{\circ} \mathrm{C}$, red sandstone, $\times 150$; (e) $-30^{\circ} \mathrm{C}$, red sandstone, $\times 150$; (f) $-40^{\circ} \mathrm{C}$, red sandstone, $\times 150$.

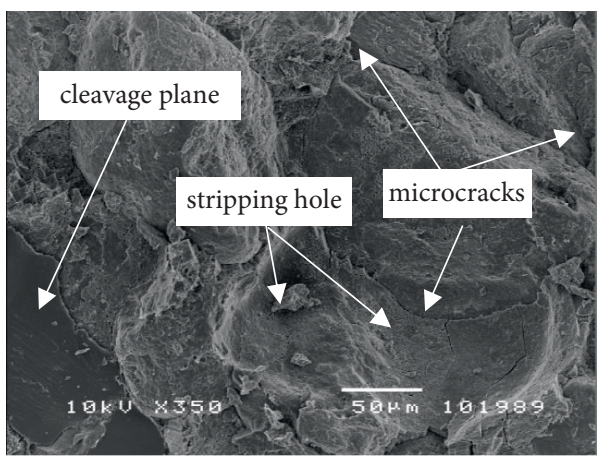

(a)

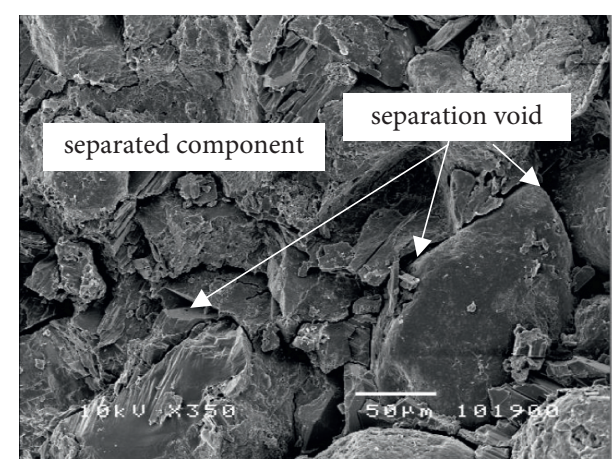

(b)

Figure 19: Local microscopic fracture morphology: (a) $-40^{\circ} \mathrm{C}$, red sandstone, $\times 350$; (b) $-30^{\circ} \mathrm{C}$, red sandstone, $\times 350$. 


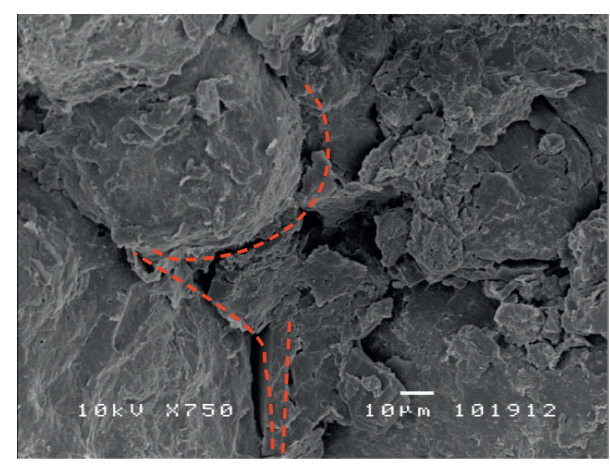

FIgURE 20: Examples of elastic incompatibility.

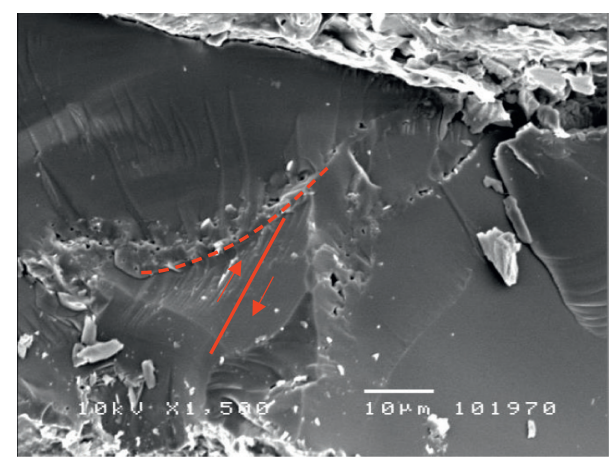

Figure 21: Example of crack nucleation caused by shear deformation.

at subzero temperature. From the microcosmic point of view, the shear deformation in the grain is caused by the sliding of a single dislocation or coordinated movement of a large number of dislocations. The resulting shear stress is confined within a shear band, but when the shear band encounters obstacles, high local stress will be generated at the shear band tip, which leads to crack nucleation. Cracks usually occur in shear bands of the same grain, but when the barrier or interface is weak and requires less energy for crack propagation, cracks can also occur at the barrier or along the interface at weak surfaces of the material (see Figure 21).

\section{Conclusions}

This paper carries out the dynamic impact test (SHPB) on red sandstone and obtains macroscopic failure characteristics and strength characteristics of red sandstone frozen at subzero temperature under impact load. Combining the results from scanning electron microscopy (SEM), the effects of dynamic load, subzero temperature, and water-ice phase transformation on the strength and deformation properties of rock were studied by fractal dimension and fracture morphology:

(1) With the decrease of subzero temperature $\left(-5^{\circ} \mathrm{C}\right.$ to $-40^{\circ} \mathrm{C}$ ), the breakage degree of red sandstone at high strain rate gradually intensifies. Meanwhile, the failure mode is changing from the initial tension failure at subzero temperature to the shear failure at lower subzero temperatures. In this experiment, the dynamic strength of red sandstone decreases sharply in the range of $-30^{\circ} \mathrm{C}$ to $-40^{\circ} \mathrm{C}$, which is different from the static test results of red sandstone under subzero temperature.

(2) Under the condition of subzero temperature, the fractal dimension of red sandstone is closely related to the dissipated energy, which shows a weak power function increasing relationship. This relationship is established based on damage fracture and irrelevant to temperature or other external conditions. The fracture energy-fractal dimension curve presents an upward convex shape, and the growth ratio represented by the slope of the curve tends to gradually slow down. The emergence and size of the threshold are related to the sieve aperture and mineral particle size.

(3) The fracture morphology analysis shows that a large number of cracks are generated at the interface between the components in red sandstone at a lower subzero temperature. Due to the low plastic deformation ability of the tip, these cracks are prone to unstable propagation under high strain rate loading, which leads to a kind of low stress brittle failure of red sandstone. However, the cement is more susceptible to subzero temperature due to its complex mineral composition. Therefore, under the multiple influential factors of dynamic load and subzero temperature, the failure of the cement usually occurs firstly, which leads to the fracture of the red sandstone [20-26].

\section{Data Availability}

The experimental data used to support the findings of this study are included within this article.

\section{Disclosure}

The funders had no role in the design of the study; in the collection, analyses, or interpretation of data; in the writing of the manuscript; and in the decision to publish the results.

\section{Conflicts of Interest}

The authors declare that they have no conflicts of interest.

\section{Authors' Contributions}

Y. Yang conceptualized the research idea; performed the methodology; validated, curated, and visualized the data; and wrote the original draft. Y. Yang, J. G. Wang, and N. N. Zhang were involved in data investigation. J. G. Wang and Y. Yang were responsible for project supervision and administration and funding acquisition. All authors read, reviewed, and edited the paper and agreed to the published version of the manuscript.

\section{Acknowledgments}

We thank the China University of Mining and Technology (Beijing) for providing instruments to conduct the research. 
Furthermore, we are very thankful for the fund provided by the key project of the National Natural Science Foundation of China (51934001).

\section{References}

[1] Q. S. Liu, S. B. Huang, Y. S. Kang, and X. Cui, "Advance and review on freezing-thawing damage of fractured rock," Chinese Journal of Rock Mechanics and Engineering, vol. 34, no. 3, p. 452, 2015.

[2] W. Z. Chen, X. J. Tan, H. D. Yu, and K. Yuan, "Advance and review on thermo-hydro-mechanical characteristics of rock mass under condition of low temperature and freeze-thaw cycles," Chinese Journal of Rock Mechanics and Engineering, vol. 30, no. 7, p. 1318, 2011.

[3] K. Aoki, K. Hibiya, and T. Yoshida, "Storage of refrigerated liquefied gases in rock caverns: characteristics of rock under very low temperatures," Tunnelling and Underground Space Technology, vol. 5, no. 4, pp. 319-325, 1990.

[4] T. Yamabe and K. M. Neaupane, "Determination of some thermo-mechanical properties of Sirahama sandstone under subzero temperature condition," International Journal of Rock Mechanics and Mining Sciences, vol. 38, no. 7, pp. 1029-1034, 2001.

[5] R. D. Dwivedi, A. K. Soni, R. K. Goel, and A. K. Dube, "Fracture toughness of rocks under sub-zero temperature conditions," International Journal of Rock Mechanics and Mining Sciences, vol. 37, no. 8, pp. 1267-1275, 2000.

[6] M. M. Tang, Z. Y. Wang, Y. L. Sun, and J. Ba, "Experimental study of mechanical properties of granite under low temperature," Chinese Journal of Rock Mechanics and Engineering, vol. 29, no. 4, p. 787, 2010.

[7] J. M. Xi, G. S. Yang, L. Pang, and X.-T. Lu, "Experimental study on basic mechanical behaviors of sandy mudstone under low freezing temperature," Journal of China Coal Society, vol. 39, no. 7, p. 1262, 2014, https://doi.org/10.13225/j. cnki.jccs.2014.0533.

[8] G. M. Xu, Q. S. Liu, W. W. Peng, and X. Chang, "Experimental study on basic mechanical behaviors of rocks under low temperatures," Chinese Journal of Rock Mechanics and Engineering, vol. 25, no. 12, p. 2502, 2006.

[9] G. S. Yang and X. T. Lü, "Experimental study on the sandy mudstone mechanical properties of shaft sidewalls under the frozen conditions," J Min Saf Eng, vol. 29, no. 4, p. 492, 2012.

[10] G. S. Yang, J. M. Xi, H. J. Li, L. Cheng, and X. T. Lv, "Experimental study on the mechanical properties of soft rock of coal mine shaft sidewalls under the frozen conditions," Chinese Journal of Underground Space and Engineering, vol. 8, no. 4, pp. 690-687, 2012.

[11] H. Wu, D. Ma, A. J. S. Spearing, and G. Y. Zhao, "Fracture phenomena and mechanisms of brittle rock with different numbers of openings under uniaxial loading," Geomechanics and Engineering, vol. 25, pp. 481-493, 2021.

[12] D. Ma, J. Zhang, H. Duan et al., "Reutilization of gangue wastes in underground backfilling mining: overburden aquifer protection," Chemosphere, vol. 264, Article ID 128400, 2021.

[13] D. Ma, J. Wang, X. Cai et al., "Effects of height/diameter ratio on failure and damage properties of granite under coupled bending and splitting deformation," Engineering Fracture Mechanics, vol. 220, Article ID 106640, 2019.

[14] D. Ma, S. Kong, Z. Li, Q. Zhang, Z. Wang, and Z. Zhou, "Effect of wetting-drying cycle on hydraulic and mechanical properties of cemented paste backfill of the recycled solid wastes," Chemosphere, vol. 282, Article ID 131163, 2021.

[15] X. B. Li and D. S. Gu, Rock Impact Dynamics, Central South University of Technology Press, Changsha, China, 1994.

[16] H. J. Li, Experimental Study On Rock Mechanical Properties Under Freezing Conditions [Dissertation], Xi'an University of Science and Technology, Xi'an, China, 2009.

[17] L. Cheng, Experimental Study On Rock Mechanical Properties Under Freezing Conditions And Application In Project [Dissertation], $\mathrm{Xi}^{\prime}$ an University of Science and Technology, $\mathrm{Xi}^{\prime}$ an, China, 2009.

[18] J. M. Xi, G. S. Yang, and X. H. Dong, "Effect of freezing temperature on mechanical properties of sandy mudstone," Journal of Chang'an University (Natural Science Edition), vol. 34, no. 4, p. 92, 2014.

[19] R. L. Shan, L. Zhang, H. Yang, Z. Jinxun, and G. Zhiming, "Experimental study of freeze-thaw properties of saturated red sandstone," Journal of China University of Mining and Technology, vol. 45, no. 5, pp. 923-929, 2016.

[20] R. L. Shan, H. Yang, J. X. Zhang, and Z. Guo, "Mechanical properties of saturated red sandstone of Meilinmiao mine under loading and unloading at negative temperatures," J Min Saf Eng, vol. 33, no. 5, p. 924, 2016, https://doi.org/10.13545/j. cnki.jmse.2016.05.025.

[21] R. L. Shan, H. Yang, Z. M. Guo, and X. Liu, "Experimental study of strength characters of saturated red sandstone on negative temperature under triaxial compression," Chinese Journal of Rock Mechanics and Engineering, vol. 33, no. 2, p. $3657,2014$.

[22] Y. P. Li and Z. Y. Wang, "Uniaxial compressive mechanical properties of rock at low temperature," Journal of University of Science and Technology Beijing, vol. 33, no. 6, p. 671, 2011.

[23] J. Y. Xu, J. S. Fan, and X. C. Lü, Dynamic Mechanical Properties of Rock with the Confining Pressure, Northwestern Polytechnical University Press, Xi' an, China, 2012.

[24] H. P. Xie, F. Gao, H. W. Zhou, and .J.-P. Zuo, "Fractal fracture and fragmentation in rocks," J Disas Prev Mitig Eng, vol. 23, no. 4, p. 1, 2003.

[25] Y. Qian, Experimental Study On Blasting Fragment-Size Of Joints Rock Mass Based on Fractal Theory [Dissertation], Wuhan University of Technology, Wuhan, China, 2005.

[26] M. Wen, J. Y. Xu, H. Y. Wang, and X. Fang, "Fractography analysis of sandstone failure under low temperature-dynamic loading coupling effects," Chinese Journal of Rock Mechanics and Engineering, vol. 36, no. 2, p. 3822, 2017. 